\title{
Studies on Phytochemical Evaluation and Antibacterial Properties of Two Varieties of Kolanut (Cola nitida) in Nigeria
}

\author{
S. Muhammad*, A. Fatima \\ Department of Biological Sciences, Usmanu Danfodiyo University, Sokoto, Nigeria \\ Email:"samdiri@yahoo.co.uk, fatimaa32000@yahoo.com
}

Received March 2014

\section{Abstract}

Kola nut is a native stimulant which is commonly chewed in many West African cultures, individually or in a group setting. It is often used ceremonially and to honour guest. Phytochemical analysis and antibacterial screening of red and white Cola nitida (kola nut) extracts were evaluated using qualitative and quantitative method. Thin layer chromatography (TLC) was used to evaluate the phenolic content. Antibacterial screening was done using agar well diffusion method against odontopathogens; (Lactobacillus sp., Corynebacterium haemolyticum, Proteus vulgans, Bacillus lentus, Streptococcus anginosus and Pseudomonas aeruginosa) obtained from stock cultures. Phytochemical screening revealed the presence of alkaloids, flavonoids, saponin, tannins, glycoside, steroids, volatile oil and balsams. Higher content of alkaloids, saponin and glycoside was obtained in the aqueous extract than the methanol for both red and white kola nut. The results of TLC analysis revealed the presence of quercetin and coumarin in red kola and keamferol and coumarin in white kola respectively. The result of antibacterial activity of red $C$. nitida showed a zone of inhibition of $18 \mathrm{~mm}$ and $23 \mathrm{~mm}$ at $60 \mathrm{mg} / \mathrm{ml}$ for aqueous extract on Proteus vulgans and Streptococcus anginosus. Similarly white kola inhibited the growth of $S$. anginosus at $90 \mathrm{mg} / \mathrm{ml}$ with a zone of $18 \mathrm{~mm}$. Methanol extract of red kola inhibited the growth of $P$. vulgans and $S$. anginosus at $60 \mathrm{mg} / \mathrm{ml}$ with a zone of $16 \mathrm{~mm}$ and $20 \mathrm{~mm}$ respectively. Acetone and ethyl acetate extracts of both red and white kola nut did not show any activity against the tested organism at all concentrations. The results obtained indicate that $C$. nitida which posses promising chemotherapeutic and antibacterial potentials respectively that could be useful against odontopathogens. The study may serve as baseline for further studies.

\section{Keywords}

Kola Nut. Phenol Zone of Inhibition and Odontopathogens

\section{Introduction}

Treatment of anaerobic infections is usually empirical but the universality of susceptibility of anaerobes to the

\footnotetext{
"Corresponding author.
}

How to cite this paper: Muhammad, S. and Fatima, A. (2014) Studies on Phytochemical Evaluation and Antibacterial Properties of Two Varieties of Kolanut (Cola nitida) in Nigeria. Journal of Biosciences and Medicines, 2, 37-42. 
usual drugs cannot always be assumed as reports of resistant strains have been growing in the literature from all over the world; [1]-[4]. There is therefore a need for continuous search for an urgent alternative to synthetic drugs. In Africa, Asia, North and South America, medicinal plants were used for the treatment of infections before the introduction of antibiotics and other modern drugs [5]-[7].

Traditional chewing sticks are commonly used especially by rural dwellers in maintaining oral hygiene [8] with about $80 \%-90 \%$ of Nigerians using chewing sticks from a variety of plants [9]. The reasons can be attributed to culture, affordability, accessibility as well as the popular thought misguided belief that natural medicines have no side effects [10]. Studies of many plant materials and standardization of the dosages have being reported [11]-[13]. Medicinal plants such as Vernonia amygdalina, Terminalia glaucesens, Nauclea latifolia, Serindeia warneckei, and kola nut are known to inhibit the activities of some anaerobic pathogens [14]. Generally, the mechanical cleansing effect and antimicrobial substances in the seed are seen as major beneficial effects of chewing this nut. The chemical composition of kola nut includes: caffeine $(2 \%-3.5 \%)$, theobromine $(1.0 \%$ 2.5\%), theophylline, phenolics (phlobaphens, epicatechin, D-catechin, tannic acid), sugar (cellulose), water [15].

Worldwide, approximately 2.43 billion people (36\% of population) have dental carries in their permanent teeth. In baby teeth it affects about 620 million ( $9 \%$ of world population) [16]. It is the primary pathological cause of tooth loss in children and about $29 \%$ - $59 \%$ of adult over the age of 50 experience dental carries [17].

Bacterial dental plaque is involved in the initiation of gingivitis and the progression of periodontitis and plaque control is of great importance in the prevention of these diseases [18]. Adequate plaque control using mechanical methods is difficult to achieve for most individuals. Therefore, a number of chemical dental plaque-control agents have been used to supplement routine oral procedure such as mouth washing or oral irrigation [19]. Antimicrobial agents such as antibiotics, enzymes, chlorhexidine and phenol have shown anti-plaque effect both in vitro and in vivo [20].

Kola nut contain caffeine, which may explain their popular use in energy tonics. Native of Africa, the nuts of this towering tree are also a traditional medicine thought to enhance male potency. Kola is listed as having aphrodisiac stimulant, cardiotonic properties in Duke phytochemical database and to maintain alertness. Kolanut is used in peace mission or to invite some highly placed personelities to an occasion. There is a popular saying in Nigeria about kolanut. "Yoruba's produce it, Hausa's chew it the most and Igbo ritualize it the most".

Considering the use of kola nut by people in Nigeria, who believe that kola nut may prevent dental plaque if proper hygiene is maintained. Also, the antimicrobial activity of phenolic compound, there is the need for thorough biochemical evaluation of kola nut with the view to obtaining the potential which could be vital in providing dental care.

The aim of the study is to evaluate the phytochemical content of kola nut and its antibacterial activity against odontopathogens.

\section{Methodology}

Two varieties of kola nut (Red and White) Cola nitida were collected from major cola nuts market across Nigeria. The plant material was authenticated at the herbarium, Department of Biological Sciences, Usmanu Danfodiyo University Sokoto. A portion of it was shaded dried and pulverized into powder using a mortar and pestle.

\subsection{Extraction of Red and White Variety of Kola Nut}

A portion of about $250 \mathrm{~g}$ of each pulverized kola nut was socked in 1liter of water, methanol, acetone and ethyl acetate each respectively in separate conical flask and corked. These were allowed to stand for $24 \mathrm{hrs,} \mathrm{filtered}$ and the powered extract was collected separately for red and white variety.

Prepared extract of Cola nitida were subjected to standard phytochemical analysis for different constituents such as tannins, alkaloids, flavonoids, anthraquinones, glycocides, Saponins and phenols as described by [21] Jigna et al. (2006). The following test were conducted Test for flavonoid Test for tannins, Test for saponin [22]. Test for glycoside and Test for alkaloids [23].

\subsection{Antibacterial Assay}

Nutrient agar was used for testing of these extracts. Three wells were made on each plate agar using sterilized 14 $\mathrm{mm}$ cork borer. Each plate agar was inoculated with different isolates separately. This was done with the use of sterilized wire loop after standardization of each inoculum. 
After inoculation, different concentration of the plant extract was mixed with little plain agar and pour into designated well which carry the specific concentration of the extract. The inoculated plates were allowed to stand for 15 minute before incubating then for 24 hours at $37^{\circ} \mathrm{C}$. In a good light and colour background the turbidity of the suspension was matched with that of the turbidity standard. The turbidity of the test inoculum was adjusted by either adding more Candida albican or more physiological saline until a good match is obtained. Minimum Inhibitory Concentration (MIC) was then conducted on positive inhibited test organisms.

\section{Results and Discussion}

The results of qualitative phytochemical screening of two varieties of kola nut are represented in Table $\mathbf{1}$. The results revealed the presence of alkaloid, saponin, and glycosides were detected in the aqueous extract of red and white C. nitida. However, saponin and steroids were detected in methanol extract while flavonoids, tannins, saponin glycoside, cardiac glycoside, anthraquinone, volatile oil and balsam were little or not detected in both aqueous and methanol extract (Table 1).

The results of quantitative phytochemical analysis of both red and white kola nut are presented in Table 2. Result shows that there was a significant difference $(\mathrm{p}<0.05)$ in the contents of tannins, saponins and phenolic in red variety compared to the white variety. From the result, it was observed that the white variety had the highest percentage of saponin with $1.10 \%$ while red had $0.90 \%$. Similarly, white variety had $0.25 \%$ phenol while red variety had $0.21 \%$. Moreover, tannins content of white variety was also high $0.12 \%$ as compared to red kola with $0.11 \%$.

The involvement of anaerobes in human infections has generated global interest in recent time. Oral environment tends to favour the growth of both aerobic and facultative anaerobic bacteria. Bacteria accumulate on both the hard and soft oral tissue in biofilms [24]. Dental plaque is a biofilm that build up on the teeth and consist of bacteria and their products all in close proximity to the surface of the teeth. The accumulation of food debris on the teeth, might give room for pathogenic bacteria to grow thereby leading to oral infections like dental carries, peridontal infections.

Kola nut is regularly chewed and by Nigerian, posses polyphenols which have been reported to exhibit antibacterial activities with distinguished characteristics in their reactivity with protein related polyamide polymer [25]. In this study, red and white variety of kola nut aqueous and methanol extracts showed antibacterial

Table 1. Results of qualitative phytochemical content of aqueous and methanol extract of red and white C. nitida.

\begin{tabular}{|c|c|c|c|c|}
\hline \multirow[t]{2}{*}{ Component } & \multicolumn{2}{|c|}{ Aqueous extract } & \multicolumn{2}{|c|}{ Methanol extract } \\
\hline & Red & White & Red & White \\
\hline Alkaloids & +++ & +++ & ND & ND \\
\hline Flavonoids & + & Trace & ND & ND \\
\hline Saponins & ++ & ++ & +++ & + \\
\hline Tannins & + & + & ND & ND \\
\hline Glycosides & ++ & +++ & + & + \\
\hline Saponin glycoside & Trace & Trace & ND & ND \\
\hline Cardiac glycoside & ND & ND & ND & ND \\
\hline Steriods & + & + & +++ & + \\
\hline Anthraquinone & ND & ND & ND & ND \\
\hline Volatile oil & Trace & Trace & + & + \\
\hline Balsams & + & + & + & + \\
\hline
\end{tabular}

Key: +++ = Present in high concentration; ++ = Moderately present; + = Slightly present; ND = not detected.

Table 2. Results of quantitative analysis of red and white Cola nitida Kola nut variety \% constituent (mg/ml).

\begin{tabular}{cccc}
\hline & Tannins & Saponins & Phenols \\
\hline White variety & 0.12 & 1.10 & 0.21 \\
Red variety & 0.11 & 0.90 & 0.25 \\
\hline
\end{tabular}


activity against Streptococcus anginosus, gram positive bacteria which, is a member of the viridian Streptococci. These are heterogenic bacteria with unique pathogenicity than other Streptococci [26]. However, red variety also showed activity against Proteus vulgans, gram negative bacteria at $60 \mathrm{mg} / \mathrm{ml}$, which gave a zone of inhibition of $18 \mathrm{~mm}$ and $16 \mathrm{~mm}$ at $60 \mathrm{mg} / \mathrm{ml}$ for methanol and aqueous extracts. Similar report was seen in the work of [27] on kola extract against Proteus mirabilis, which gave an inhibition zone of $16 \mathrm{~mm}$ at $1000 \mu \mathrm{g} / \mathrm{ml}$.

The inhibition of micro-organisms by kola nut which contain phenolic compounds may be due to iron deprivation or hydrogen bonding with vital proteins such as micro- enzyme. Coumarine, quercetin and kaeferol which might be present in kola nut as detected from the TLC ran on both red and white varieties, are belief to posses inhibitory characteristics against gram positive and gram negative bacteria [28]. Though inhibition was not observed on other odontopathogens used in this study that is (Lactobacillus sp, Corynebacterium haemolyticum, Bacillus lentus and Pseudomonas aeruginosa). C. nitida inactivity exhibited against these organisms and also that of acetone and ethyl acetate extract of both red and white variety, may be due to the absence of inhibitory alkaloids against the tested organisms. This is because alkaloids have been chained to be responsible for antimicrobial effect [29] [30]. However, the inactivity may not be justified that no other bioactive agent present in the extract. This is similar to the report of [31], who showed that no active substance exhibited its maximum activity under laboratory experimental condition. Therefore, if there is increase in concentration these may enhance activity.

Preliminary qualitative test is useful in the detection of bioactive principles and subsequently may lead to drug discoveries and development [32] [33] conducted phytochemical screening of leaves of twenty eight woody species from different plants families in Nigeria and discovered the presence of tannins, alkaloids and flavonoids in all samples, thus these secondary metabolites seem to be cosmopolitan in plants but, in varying degrees and type.

In this study, the presence of alkaloids, saponins, and glycoside were present in aqueous extract of both red and white kola nut. However, saponin and steroid were denser in methanol extract of red kola nut. Anthraquinone and cardiac glycoside were not detected in both extracts of red and white $C$. nitida. This is similar to the finding of [34] on some Niger Delta plants who observed the presence of flavonoid, tannins, alkaloids and saponin in large quantity. The presence of alkaloids and saponins might also explain the therapeutic properties of this plant, since alkaloid-containing plant has been used by humans since ancient times for therapeutic and recreational pursoses [35].

\section{Conclusions}

Phytochemical investigation of Cola nitida traditionally used in Nigeria revealed the presence of medicinal naturals. kaemferol, quercetin and coumarin were identified by using simple TLC method. The qualitalitative analysis also revealed the presence of alkaloids, flavonoids, saponin, tannins, steroids, volatile and balsam. These result showed varying degrees of antibacterial activities on some odontopathogens.

The red kola aqueous and methanol extract impaired the growth of Proteus vulgans and Streptococcus anginosus. These organisms help in plague formation therein, initiates different dental problems.

The C. nitida extract showed its potential in the impairment of growth of test isolates and can serve as an alternative remedy for oral infections. This is a step forward for further evaluation of the plant for bio-remedies.

Recommendation

Based on the result of the study, the following recommendations are provided:

1) Considering the antibacterial activity of red Cola nitida further studies should be carried out on odontopathogens and how best it can be recommended for use against dental infections.

2) The phenolic compounds present in C. nitida should be isolated, purified and tested to obtain their maximum therapeutic potentials.

3) Vigorous research work should be geared towards the investigating the antimicrobial potential of Cola nitida, for harnessing the numerous volatile compounds from the plant for industrial uses to better the lots of humanity.

\section{References}

[1] Nyfors, S., Kononen, E., Syrjanen, A.R., Komulainen, E. and Jousimies-Somer, H. (2003) Emergence of Penicillin Resistance among Fusobacterium nucleatum of Commensal Oral Flora during Early Childhood. Journal of Antimicrobial 
Chemotherapy, 51, 107-112. http://dx.doi.org/10.1093/jac/dkg022

[2] Roberts, S.A., Shore, K.P., Paviour, S.D., Holland, D. and Morris, A.J. (2006) Antimicrobial Susceptibility of Anaerobic Bacteria in New Zealand. Journal of Antimicrobial Chemotherapy, 57, 992-998. http://dx.doi.org/10.1093/jac/dkl052

[3] Al-Haroni, M. and Skaug, N. (2007) Incidence of Antibiotic Prescribing in Dental in Norway and Its Contribution to National Consumption. Journal of Antimicrobial Chemotherapy, 59, 1161-1166. http://dx.doi.org/10.1093/jac/dkm090

[4] Kommedal, O., Nystad, T.W., Bolstad, B. and Digranes, A. (2007) Antibiotic Susceptibility of Blood Culture Isolates of Anaerobic Bacteria at a Norwegian University Hospital. APMIS, 115, 956-961. http://dx.doi.org/10.1111/j.1600-0463.2007.apm_537.x

[5] Haslam, E., Lilley, T.H., Ya Cai, R., Martin, R. and Magnolato, D. (1989) Traditional Herbal Medicine. The Role of Polyphenols. Planta Medica., 55, 1-8. http://dx.doi.org/10.1055/s-2006-961764

[6] Lee, S.S., Zhang, W. and Li, Y. (2004) The Antimicrobial Potential of 14 Natural Herbal Centifrices. Results of an in Vitro Diffusion Method Study. Journal of American Dentistry Association, 135, 1133-1141. http://dx.doi.org/10.14219/jada.archive.2004.0372

[7] Lima, M.R.F., Luna, J.S., Santos, A.F., Andrade, M.C.C., Sant’Ana, A.E.G., Genet, J.P., Marquez, B., Neuville, L. and Moreau, N. (2006) Anti-Bacterial Activity of Some Brazilian Medicinal Plants. Journal of Ethnopharmacology, 105, 137-147. http://dx.doi.org/10.1016/j.jep.2005.10.026

[8] Ndukwe, K.C., Okeke, I.N., Lamikanra, A., Adesina, S.K. and Aboderin, O.J. (2005) Antibacterial Activities of Aqueous Extracts of Selected Chewing Sticks. Journal of Contemparary Dental Practise, 3, 86-94.

[9] Soto, E.O. and Wilson, M. (1995) In Vitro Antimicrobial Effects of Extracts of Nigerian Tooth Cleaning Sticks on Periodopathic Bacteria. African Dental Journal, 9, 15-19.

[10] Lima, M.R.F., Luna, J.S., Santos, A.F., Andrade, M.C.C., Sant’Ana, A.E.G., Genet, J.P., Marquez, B., Neuville, L. and Moreau, N. (2006) Anti-Bacterial Activity of Some Brazillian Medicinal Plants. Journal of Ethnopharmacology, 105, 137-147. http://dx.doi.org/10.1016/j.jep.2005.10.026

[11] Ndukwe, K.C., Okeke, I.N., Lamikanra, A., Adesina, S.K. and Aboderin, O.J. (2005) Antibacterial Activities of Aqueous Extracts of Selected Chewing Sticks. Journal of Contemporary Dental Practise, 3, 86-94.

[12] Odugbemi, T. (2006) Introduction. In: Odugbemi, T., Ed., Outlines and Pictures of Medicinal Plants from Nigeria, University Press, Lagos, 1-4.

[13] Ogbulie, J.N., Ogueke, C.C. and Nwanebu, F.C. (2007) Antibacterial Properties of Uvaria chamae, Congronema latifolium, Garcinia kola, Vemonia amygdalina and Aframomium melegueta. African Journal of Biotechnology, 6, 15491553.

[14] Ugoji, E., Egwari, L.O. and Obisesan, B. (2000) Antibacterial Activities of Aqueous Extracts of Ten African Chewing Sticks on Oral Pathogens. Nigeria Journal of International Medicine, 3, 7-11.

[15] Kim and Katherine (2001) Encyclopedia of Alternative Medicine.

[16] Vos, T. (2012) Years Lived with Disability (YLDs) for 1160 Sequelae of 289 Diseases and Injuries 1990-2010: A Systematic Analysis for the Global Burden of Disease Study 2010. Lancet, 380, 2163-2196. http://dx.doi.org/10.1016/S0140-6736(12)61729-2

[17] WHO (2006) The World Oral Health Report 2003: Continuous Improvement of Oral Health in the 21st Century-The Approach of the WHO Global Oral Health Programme.

[18] Adeniyi, B.A., Groves, M.J. and Gangadharam, P.R.J. (2004) In Vitro Anti Mycobacterial Activities of Three Species of Cola Plant Extract (Sterculiaceae). Phytotherapy Research, 18, 414-418. http://dx.doi.org/10.1002/ptr.1468

[19] Ajaiyeoba, E.O. and Sama, W. (2006) Phytochemical and Antimicrobial Studies of Capparis thonningii and Capparis tomentosa. Pharmacognosy Magzine, 2, 119-122.

[20] Ajaiyeoba, E.O. and Sama, W. (2006) Phytochemical and Antimicrobial Studies of Capparis thonningii and Capparis tomentosa. Pharmacognosy Magzine, 2, 119-122.

[21] Jigna, P., Nehal, K. and Sumitra, C., (2006) Evaluation of Antibacterial and Phytochemical Analysis of Bauhima variegate L. Bark. African Journal of Biomedical Research, 9, 53-56.

[22] Trease, G.E. and Evans, W.C. (1978) Pharmacognosy, 11th Edition, Bailluere Tindall, London.

[23] Epega, A.A. (2003) Obi Divination. Athelia Henrietta Press, 1-2FAMA Aina Adewale-Somadhi, Chief: (2004), Practitioner's Handbook for the IFA Professional, Ile Orunmila Communications, 1.

[24] Roger, A.H. (2008) Molecular Oral Microbiology. Carster Academic Press.

[25] Haslam, E. (1996) Natural Polyphenols (Vegetable Tannins) Asdrug: Possible Mode of Action. Journal of National Products, 59, 205-215. http://dx.doi.org/10.1021/np960040+ 
[26] Ryan, K.J. and Ray, C.G. (2004) Sherris Medical Microbiology, 4, 293-294.

[27] Saravana kumar, A., Venkateshwarank, Vanitha, J., Vasudevan, M. and Sivakumar, T. (2009). An Evaluation of Antibacterial Activity of Phenol and Flavonoid Content of Thespesia populnea Flower Extract. Pakistan Journal of Pharmacological Science, 22, 282-286.

[28] Kawase, M., Varu, B., Shah, A., Motohashi, N., Tami, S., Saito, S., Debnath, S., Mahapatra, S., Dastidar, S.G. and Chakrabarty, A.N. (2001) Antibacterial Activity of New Caumarine Derivatives. George Thieme Verlag Stuttgard, New York. Pubmed.gov., 51, 67-71.

[29] Lahane, B. (1977) The Power of Plant. Oxford University Press, Oxford.

[30] Waller, G.R. and Nowaki, E.R. (1978) Alkaloids Production and Metabolism in Plants Plenum Press, New York. 2: 56-60

[31] Burger, A. (1990) The Role of Natural Compounds in Medicinal Chemistry. 3rd Edition, John Wiley and Sons, Hoboken, 81-84.

[32] Malikharjuna, P.B., Rajana, L.N., Seetharam, Y.N. and Sharanabasappa, G.K. (2007) Phytochemical Studies of Strychnos potatorum L. F. A Medicinal Plant. Environmental Journal of Chemistry, 4, 510-518.

[33] Olawole, A.F. (2007) Phytochemical Screening and Mineral Content of Leaves of Some Nigerian Woody Plants. Research Journal of Phytochemical, 16, 13-16.

[34] Nyananyo, B.L., Menslah, S.I. and Achama, C. (2010) Phytochemical Investigation of Some Tropical Plants from Niger Delta Area Nigeria. Science Africa, 9, 179-180.

[35] Aniszewski, T. (2007) Alkaloids Secrets of Life. Amsterdam, 182. 